\title{
Isabelle de Charrière écrivaine politique/Belle de Zuylen political writer
}

\section{Paola Perazzolo}

\section{(2) OpenEdition}

1 Journals

\section{Edizione digitale}

URL: http://journals.openedition.org/studifrancesi/9969

DOI: 10.4000/studifrancesi.9969

ISSN: 2421-5856

\section{Editore}

Rosenberg \& Sellier

\section{Edizione cartacea}

Data di pubblicazione: 1 août 2017

Paginazione: 362

ISSN: 0039-2944

\section{Notizia bibliografica digitale}

Paola Perazzolo, «Isabelle de Charrière écrivaine politique/Belle de Zuylen political writer», Studi Francesi

[Online], 182 (LXI | II) | 2017, online dal 01 août 2017, consultato il 05 janvier 2021. URL: http:// journals.openedition.org/studifrancesi/9969; DOI: https://doi.org/10.4000/studifrancesi.9969

Questo documento è stato generato automaticamente il 5 janvier 2021.

\section{(c) (i) (9)}

Studi Francesi è distribuita con Licenza Creative Commons Attribuzione - Non commerciale - Non opere derivate 4.0 Internazionale. 


\section{Isabelle de Charrière écrivaine politique/Belle de Zuylen political writer}

Paola Perazzolo

\section{NOTIZIA}

Isabelle de Charrière écrivaine politique/Belle de Zuylen political writer, «Cahiers Isabelle de Charrière/Belle van Zuylen Papers» 9, 2014, 146 pp.

1 Il presente numero dei «Cahiers Isabelle de Charrière/Belle de Zuylen Papers» - dal 2006 continuazione della «Lettre de Zuylen et du Pontet» (1976-2005) pubblicata dalla Société Isabelle de Charrière - che presentiamo con un ritardo di cui ci scusiamo, verte sull'attività di «écrivaine politique» che «la dame du Pontet» ha svolto in un'epoca in cui la riflessione sulla res publica sembrava essere appannaggio essenzialmente degli uomini. Come si fa osservare nella Présentation del numero della rivista in esame, l'interesse per la politica sottende in modo importante una corrispondenza e una produzione - pamphlets, essais, romanzi, pièces - costantemente nutrite da «une réflexion critique sur les pouvoirs en place, accompagnée d'une interrogation sur les qualités requises de celui ou ceux qui exerce/nt ce pouvoir» (p. 9). Tale interesse non può che essere accresciuto dalle congiunture storico-politiche europee della fine del secolo, su cui si concentrano quasi tutti gli scritti presi in esame nel presente volume. In La Réponse à l'écrit du colonel de la Harpe d'Isabelle de Charrière: un pamphlet aux limites du genre (pp. 14-38), Virginie PASCHE sottolinea la reattività dell'A. al contesto coevo: l'eventualità che il Pays de Vaud, o la Svizzera tutta, diventino nel 1797 una «République sœur» della Francia rivoluzionaria origina infatti la composizione della refutazione politica succitata, che gode tuttavia di una ricezione molto limitata: il critico mostra infatti come la prospettiva femminile adottata, pur se coperta dall'anonimato, abbia nuociuto a un testo non scevro di argomentazioni audaci quali la comparazione tra due categorie parimenti escluse dall'esercizio del potere - i Vaudois, 
sudditi delle autorità bernesi, e le donne, sottomesse all'autorità maritale. Paola PERAZZOLO ("Quiconque lirait l'Émigré, l'Inconsolable, Brusquet et Elise, me lirait moi à peu de choses près»: la parfaite liberté d'Isabelle de Charrière, pp. 39-54) prende in considerazione $\mathrm{i}$ rapporti tra la pièce di circostanza La Parfaite Égalité ou les tu et les toi di Dorvigny e la continuazione ideale composta dalla dame du Pontet. Helder mendES BAIAO (La part précieuse de la beauté du monde: l'économie de Mme de Charrière, pp. 54-71) raffronta invece le Observations et conjectures politiques (1787-1788), uno scritto politico riguardante $\mathrm{i}$ sommovimenti patriottici olandesi, con altri essais come le Lettres d'un évêque français à la nation (1789): in entrambi i casi, Charrière insiste sul senso di responsabilità individuale e sulla necessità di una migliore distribuzione della ricchezza suggerendo un «dispositif de mesures [...] présenté comme un socle politique et moral éloignant l'instabilité sociale et procurant le bonheur des individus» (p. 70). Peter ALTENA (Averse to insincerity: nobility in satirical work by Belle van Zuylen, Gerrit Paape and contemporaries, pp. 72-85) si occupa invece dei contes Le Noble e Bien-Né, evidenziando le similarità degli stessi con opere olandesi coeve in cui la concezione dell'aristocrazia risulta apparentabile a quella dell'autrice.

2 Completano il volume l'articolo Numériser la correspondance charriérienne (suite): le cas de la "morgue bernoise" (pp. 86-93) in cui Maria Schouten e Suzan van Dijk presentano i progressi dell'imponente lavoro di digitalizzazione della corrispondenza e le possibilità di ricerca fornite dalla prossima edizione digitale della stessa, alcune recensioni di studi recenti, l'annuale Aperçu bibliographique/Bibliographical Notes curato da Madeleine van Strien-Chardonneau (pp. 102-106) e la presentazione delle numerose attività promosse dall'Association Isabelle de Charrière/Genootschap Belle van Zuylen. 